\title{
Study of electropulse heat treatment of cold worked NiTi wire: From uniform to localised tensile behaviour
}

\author{
V. Delobelle*, G. Chagnon, D. Favier, T. Alonso \\ TIMC-IMAG UMR 5525, Grenoble, France
}

\begin{abstract}
Electropulse heat treatment is a technique developed to realise fast heat treatment of NiTi shape memory alloys. This study investigates mechanical behaviour of cold worked NiTi wires heat treated with such a technique. It is demonstrated that milliseconds electropulses allow to realise homogeneous heat treatments and to adapt the mechanical behaviour of NiTi wires by controlling the electric energy. The material can be made elastic with different elastic modulus, perfectly superelastic with different stress plateau levels and superelastic with important local residual strain. Due to the short duration and high temperature of the heat treatment, this technique allows to obtain mechanical properties that cannot be obtained with classical heat treatments of several minutes in conventional furnaces such as linear evolution of the final loading and high tensile strength to $1500 \mathrm{MPa}$ for superelastic material or increase of the stress plateau level with cycling for superelastic material.
\end{abstract}

\section{Introduction}

Since several years, NiTi shape memory alloys (SMA) are the most widely used SMA in engineering fields as reported by Van Humbeeck (1999), but more especially for biomedical applications as reviewed by Duerig et al. (1999) due to their excellent mechanical properties, corrosion resistance and biocompatibility. To design their applications, engineers use industrial basic components such as NiTi wires, tubes or plates. These components are generally shaped with several successive hot and cold rolling operations. During these operations, the material is severely deformed causing important grain size reduction, amorphisation of the material, and finally leading to a suppression of the phase transformation which confers the unique superelastic or ferroelastic properties to SMA as shown in Jiang et al. (2013). To restore these properties, annealing and ageing treatments are classically used as shown in Jiang et al. (2014) for example. These heat treatments are generally long, classically $60 \mathrm{~min}$ for annealing and 10-120 min for ageing step as proposed in Jiang et al. (2009) for example. Such heat treatments are performed in conventional furnace so the entire sample is heat treated homogeneously.

Recent studies investigated heat treatments of NiTi wires with Joule effect. Duration of such heat treatments is very dispersed. Zhu

\footnotetext{
* Corresponding author.

E-mail address: Vincent.Delobelle@imag.fr (V. Delobelle).
}

et al. (2014) proposed heat treatment of several minutes duration, Wang et al. (2009) and Malard et al. (2011) of seconds duration and Delville et al. (2010) studied milliseconds heat treatments. Interest of such heat treatments is twofold: (i) reducing the time of heat treatment and (ii) performing local heat treatment. This last point is of key interest to realise architectured materials with multiple or graded mechanical properties as obtained in Meng et al. (2013) with 300 s heat treatment. For milliseconds heat treatments, Delville et al. (2010, 2011) focused on the microstructures observation of the material and few informations are available about transformation and mechanical properties of the created materials. Moreover, Delville et al. (2010) mentioned the presence of an important gradient during cooling phase of their heat treatments but the structure is supposed homogeneous. For longer heat treatments proposed in Meng et al. (2013), when a thermal gradient is applied to the sample, the material has graded mechanical properties. Thus, for milliseconds heat treatments, it is important to analyse the homogeneity of the created material from a mechanical point of view.

In this study, heat treatments are realised with milliseconds electropulse. Investigation of the transformation and mechanical behaviours of the heat treated part of the NiTi SMA wires is realised. Transformation behaviour is studied by means of differential scanning calorimetry technique. Local mechanical behaviour is studied by means of digital image correlation (DIC) technique. Investigation of strain fields allows to study the impact of the heat treatment on the uniformity of the mechanical behaviour. In 


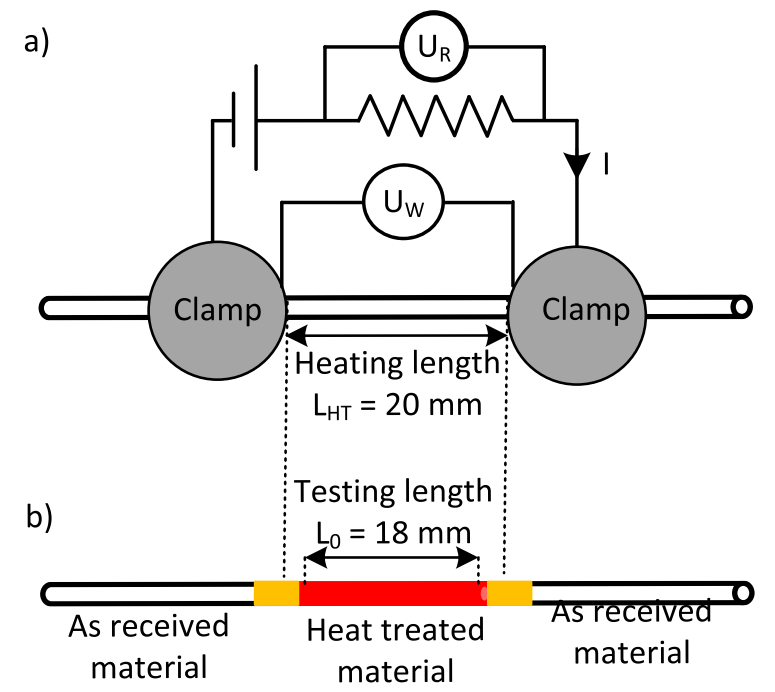

Fig. 1. a) Experimental set-up presentation. (b) Resulting material with local heat treatment.

Section 2, experiments and methods are presented. In Section 3, results are described and discussed in Section 4.

\section{Experiments and methods}

\subsection{Electropulse heat treatment}

The experiments were performed on cold worked Ti-50.8 at.\% Ni SMA wire of diameter $0.5 \mathrm{~mm}$, from the commercial provider Fort Wayne Metals ( $\mathrm{NiTi} \#$ ). The as-received material was in $45 \%$ cold worked condition. Short time electrical pulses were generated with a direct current welder (commercial ref.: DC160, Sunstone Engineering) in wire of length $L_{H T}=20 \mathrm{~mm}$, as shown in Fig. $1 \mathrm{a}$. The wire was maintained with two massive brass grips. Brass grips conduce electricity to the sample and act as a thermal mass. Thus, as shown in Fig. 1b, after heat treatment, the tips of the wire are unchanged and the centre is heat treated. In this study, six heat treatments, called A, B, C, D, E and F were carried out.

During the heat treatment, voltage $U_{W}$ at the sample terminals and voltage $U_{R}=R I$ at the resistance terminal are measured, with $R$ the resistor value and $I$ the electrical current in the electrical loop, as shown in Fig. 1 a. Power $P=U_{W} I$ dissipated in the wire is estimated. Evolutions of $U_{W}, I$ and $P$ are presented in Fig. 2a, b, c, respectively. The dissipated power is almost constant during the heat treatment and equal to $P=3000 \mathrm{~W}$. From these measurements, heat treatment duration $T$ and final dissipated energies in the wire $E=t P$ are estimated and summarised in Table 1 for all treatments. Note that the decrease of $U w=R_{\text {wire }} I$ (Fig. $2 \mathrm{a}$ ), where $R_{\text {wire }}$ is the wire electrical resistance, is in good agreement with Delville et al. $(2010,2011)$ that observed significant decrease of the electrical resistance of the wire during pulse annealing.

Table 1

Heat treatments parameters: duration, energy and estimated temperature.

\begin{tabular}{llcc}
\hline Material & $t(\mathrm{~ms})$ & $E(\mathrm{~J})$ & $T_{\max }\left({ }^{\circ} \mathrm{C}\right)$ \\
\hline CW & 0 & 0 & - \\
A & 1.44 & 4.3 & 380 \\
B & 2.27 & 6.8 & 570 \\
C & 3.08 & 11.2 & 760 \\
D & 3.99 & 12.1 & 970 \\
E & 5.04 & 14.1 & 1200 \\
F & 6.10 & 18.3 & 1440 \\
\hline
\end{tabular}
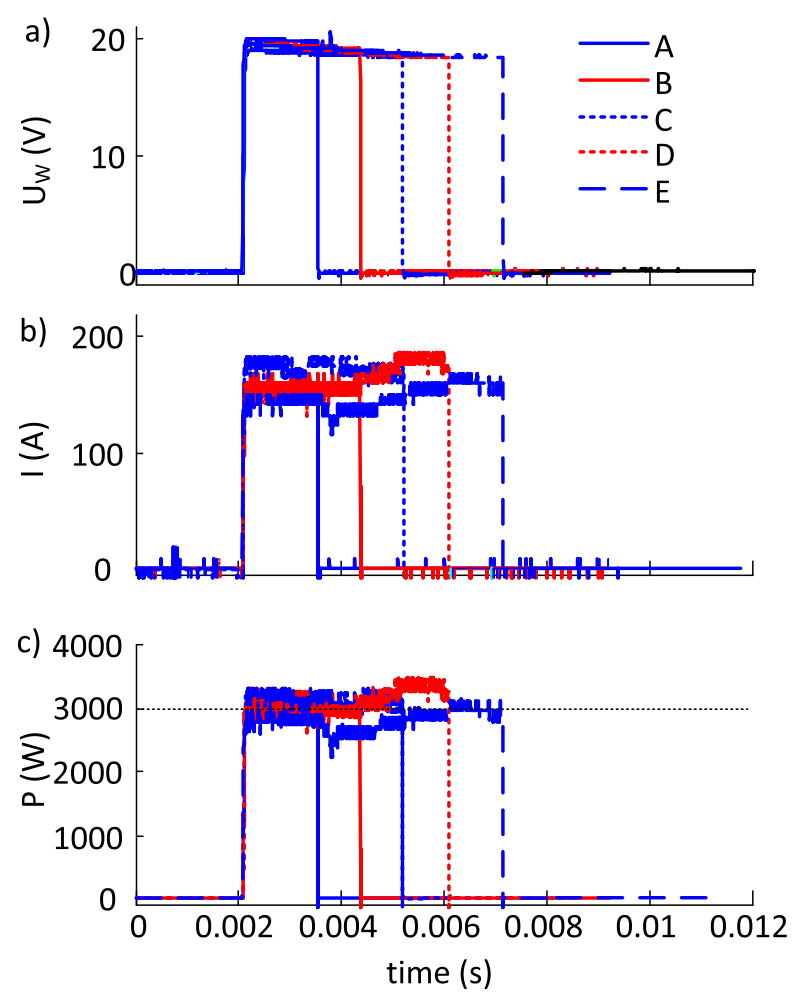

Fig. 2. Evolution of (a) Voltage $U_{W}$, (b) electrical current $I$ and (c) power $P$ during electropulse heat treatment.

An infrared camera associated to a high magnification lens (Commercial reference: Camera SC 7600, Flir) was used to record images of the wire during tests. Due to the symmetry of the experimental setup, measurements are presented only on the half of the wire. Then, due to the unknown variation of the wire emissivity during tests, only radiation values are presented. Fig. 3a shows the maximal wire radiation for tests $A$ to $E$, obtained at the end of heating and measured along the main axis of the sample $\vec{y}$. Fig. $3 \mathrm{~b}$ shows the wire radiation measured along the main axis of the sample $\vec{y}$ during cooling of test $\mathrm{D}$, from the maximal radiation obtained to room temperature. For all tests at the end of heating (Fig. 3a), close to the clamps, a strong thermal gradient is observed on $1 \mathrm{~mm}$, due to the heat loss into the clamps. It is assumed that the bump observed between 1 and $5 \mathrm{~mm}$ is due to a reflection of the wire itself via the clamp to the camera which increases the radiation. Then, between 1 and $10 \mathrm{~mm}$, the radiation and thus the temperature are uniform for all tests. Note that for test E presented in Fig. 3a, the plateau observed between 2 and $7 \mathrm{~mm}$ is due to a saturation of the infra-red sensors.

During cooling (Fig. 3b), the observed gradient is due to the presence of the clamps acting as thermal mass, and increasing the cooling rate close to them. From this observation, it can be supposed that heat treatment is heterogeneous during the cooling phase.

To estimate the sample temperature during the experiment, it is considered that the wire is submitted to: (i) step electrical power pulse $P=3000 \mathrm{~W}$, of duration equal to times indicated in Table 1 presented in full lines in Fig. 4 and (ii) radiation and convection heat losses. During heating, the sample temperature is supposed uniform as observed in Fig. 3a. Thus, the sample temperature was estimated by solving the following heat diffusion equation:

$m C(T) \frac{d T(t)}{d t}=P(t)-A h\left(T(t)-T_{0}\right)-A \epsilon \sigma T^{4}(t)$

where $m$ is the sample mass, $C$ the heat capacity taking in Smith (1993), depending of the sample temperature $T$ at instant $T, A$ the 
a)

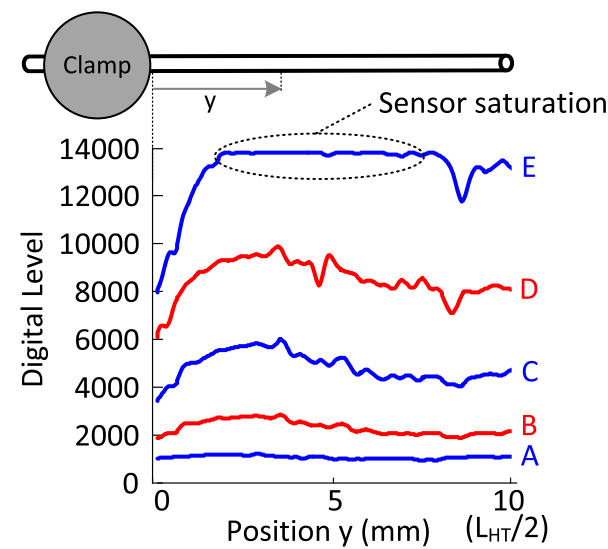

b)

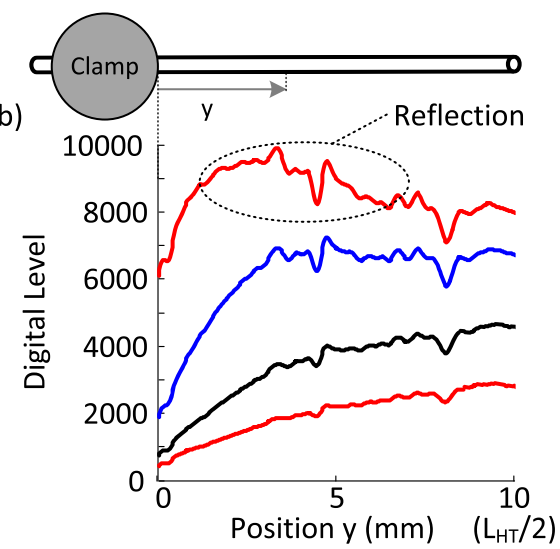

Fig. 3. Radiation measured with an infrared camera. (a) Radiation at the end of heating for tests A to E. (b) Radiation during cooling phase of test D.

lateral surface area of the sample, $h=15 \mathrm{~W} \mathrm{~m}^{-2} \mathrm{~K}^{-1}$ the convection coefficient, $T_{0}=20^{\circ} \mathrm{C}$ the room temperature, $\epsilon=0.3$ the emissivity of the sample supposed constant and $\sigma$ the Stephan-Boltzmann constant. Temperature evolutions during heat treatments A to $\mathrm{F}$ are presented in Fig. 4a. From these estimations, maximum temperatures $T_{\max }$ obtained at the end of the electropulse are summarised in Table 1 . The maximum temperature estimated for heat treatment $F$ is $T_{F}=1440^{\circ} \mathrm{C}$ which is superior to the melting temperature of almost equiatomic NiTi SMA $T_{\text {melting }}^{\text {NiTi }}=1310^{\circ} \mathrm{C}$. Experimentally, it was observed that the sample melt for such a pulse. Thus, experimental observation and theoretical approximations of the temperature are in good agreement. Due to the melting of the sample, experimental results cannot be presented for heat treatment F. The cooling time of the wire to room temperature is comprised between 40 and $50 \mathrm{~s}$ as shown in Fig. $4 \mathrm{~b}$. It remains important to keep in mind that these values are only estimations.

As shown in Fig. 1b. the resulting wire is a material having two properties. However, from Fig. 3, due to an important temperature gradient at the junction of the two materials, it can be assumed that a gradient of property is also present between the two materials. Nevertheless, this study only focuses on the transformation and mechanical behaviours of the part of the wire heat treated homogeneously.

\subsection{Transformation and mechanical behaviours study}

The transformation behaviour of materials was studied by means of DSC. DSC experiments were performed with a TA Q200 DSC between 90 and $-90^{\circ} \mathrm{C}$ with heating/cooling rate of $10^{\circ} \mathrm{Cmin}^{-1}$. The transformation behaviour of the wire was then studied between 80 and $-70^{\circ} \mathrm{C}$, when the cooling ramp is stabilised. DSC measurements were realised for all the specimens.

All the tensile tests were performed using a Gabo Eplexor tensile machine. The tests were realised at room temperature $T_{0} \approx 25^{\circ} \mathrm{C}$, at constant cross head velocity $\dot{U}=0.1 \mathrm{~mm} \mathrm{~min}^{-1}$, where $U$ is the cross head displacement. The initial gauge length of the wire was $L_{0}=18 \mathrm{~mm}$, thus, the applied global strain rate was $\dot{U} / L_{0}=9.3 \times$ $10^{-5} \mathrm{~s}^{-1}$. In this study the transition zone between heat treated material and as received material is not studied (Fig. 1b). During the tensile test, the axial force $F$ was recorded. The nominal stress $\sigma=F / S_{0}$, where $S_{0}$ is the initial cross section of the wire is calculated. In this study, the local strain field $\epsilon_{y y}$ was estimated by means of DIC method. The strain field is averaged along the main axis of the sample, in order to obtain the global strain of the material, noted $\epsilon$ in the following study.

\section{Results}

In the following, the cold worked material is noted $\mathrm{CW}$. Then, CW material heat treated with pulses $\mathrm{A}, \mathrm{B}, \mathrm{C}, \mathrm{D}, \mathrm{E}$ are called material A, B, C, D, E, respectively.

\subsection{Transformation behaviour}

Fig. 5 shows the transformation behaviour for CW, A, B, C, D and E materials.

Transformation behaviour of CW is plat and does not exhibit any peak (Fig. 5a). This result is in good agreement with Kurita et al. (2004). The transformation behaviour of material A remains plat (Fig. 5b).
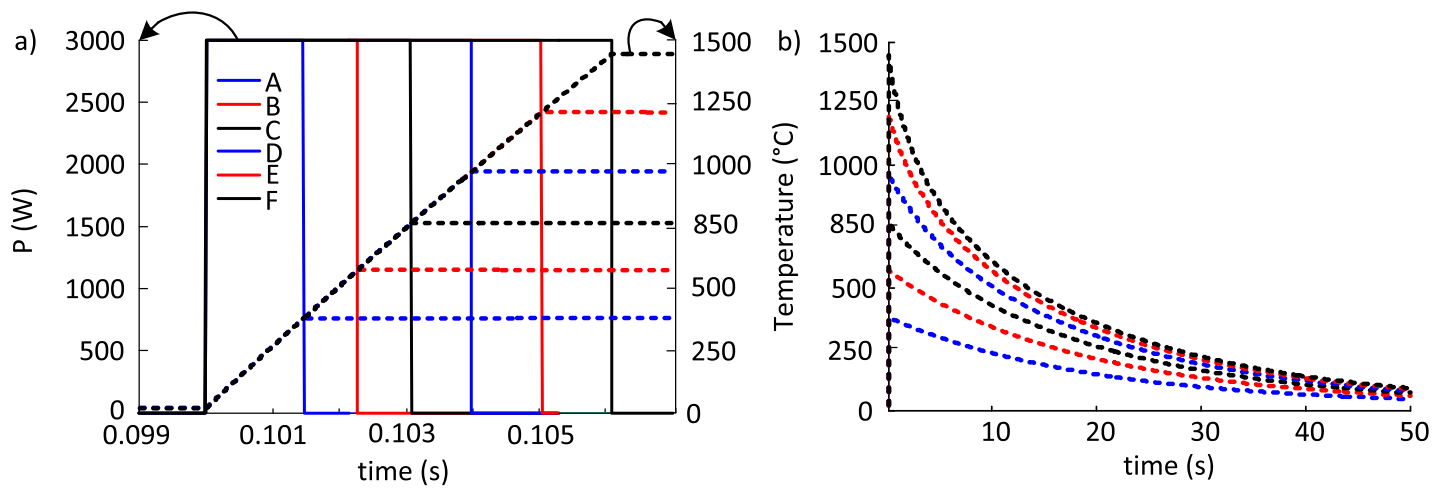

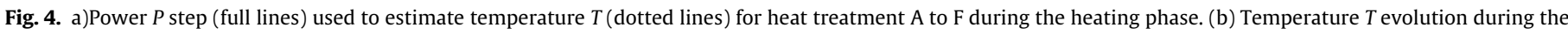
cooling phase. 


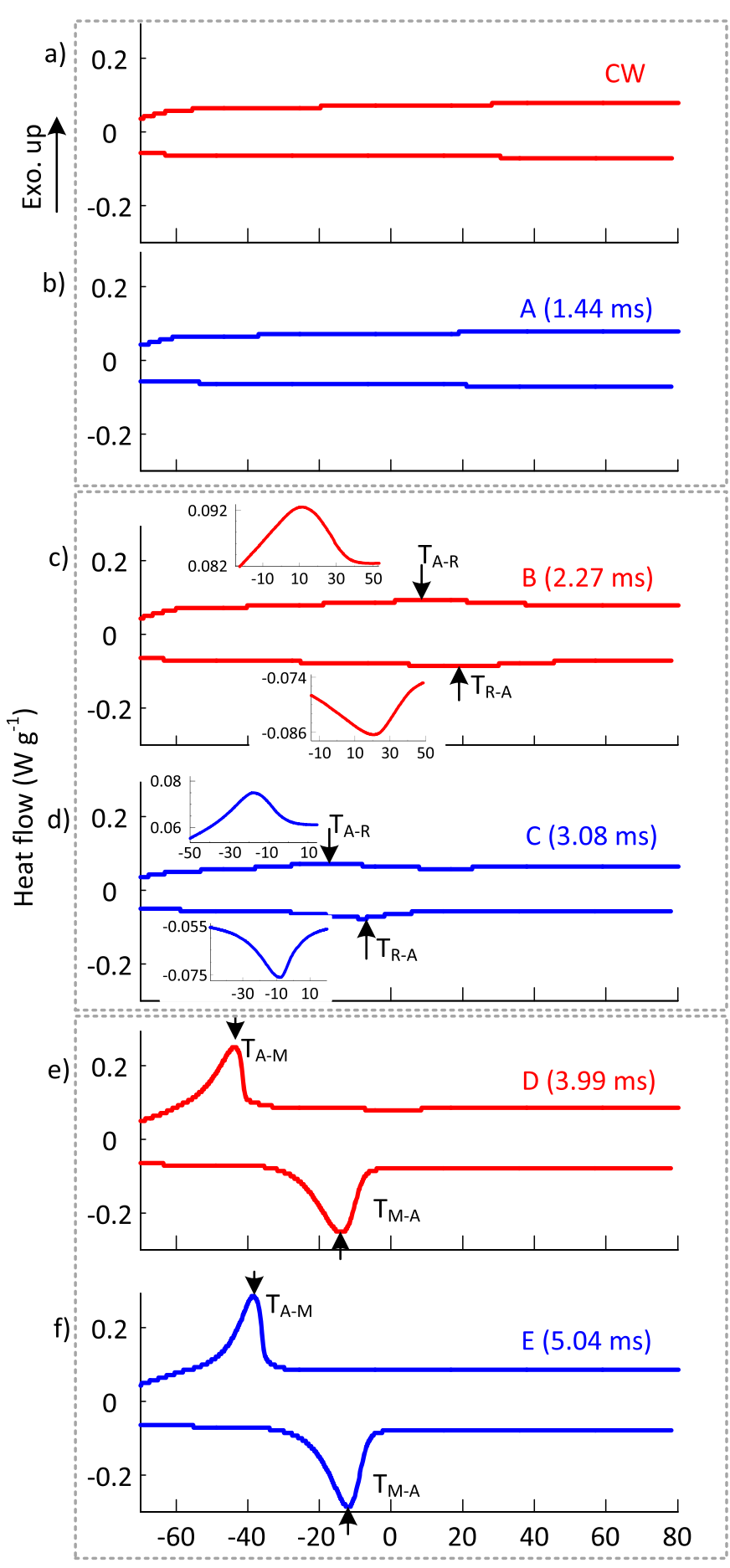

Temperature $\left({ }^{\circ} \mathrm{C}\right)$

Fig. 5. DSC of (a) material CW, (b) material A, (c) material B, (d) material C, (e) material D, and (f) material E.

A small peak is observed for material $B$, as sketched on the close up of Fig. 5c. A difference of $10^{\circ} \mathrm{C}$ between heating and cooling peak temperatures and small heat of transformation of $2.8 \mathrm{~J} \mathrm{~g}^{-1}$ are well the signature of the austenite $-R$ phase transformation (noted $A-R$ ). The transformation peak temperature at cooling and heating are about $T_{A-R}=10^{\circ} \mathrm{C}$ and $T_{R-A}=20^{\circ} \mathrm{C}$, respectively. For material $\mathrm{C}$ (Fig. 5d), a $A-R$ transformation is observed with heat of transformation estimated to approximately $2.5 \mathrm{~J} \mathrm{~g}^{-1}$ at cooling and heating. Transformation peak temperatures at cooling and heating are lower than with treatment B with $T_{A-R}=-18^{\circ} \mathrm{C}$ and $T_{R-A}=-7^{\circ} \mathrm{C}$, respectively.

For material D (Fig. 5e), the Austenite-Martensite (noted $A-M)$ transformation is observed with peak transformation temperatures equal to $T_{A-M}=-44^{\circ} \mathrm{C}$ and $T_{M-A}=-14^{\circ} \mathrm{C}$. Direct and reverse heat of transformations are estimated to be $11.0 \mathrm{Jg}^{-1}$ and $13.5 \mathrm{Jg}^{-1}$, respectively. Almost identical transformation behaviour is observed for material $\mathrm{E}$ (Fig. 5f) with a A-M transformation having heat of transformation equal to the ones found for material $D$. However, the peak transformation temperatures are higher than material $\mathrm{D}$ ones and are equal to $T_{A-M}=-38^{\circ} \mathrm{C}$ and $T_{M-A}=-12^{\circ} \mathrm{C}$.

\subsection{Mechanical behaviour}

Mechanical tests presented in Fig. 6 are composed of a loading-unloading cycle and a final loading to failure. Fig. 6a shows the global mechanical behaviour of CW material and material A. For material A, strain profiles estimated along the main axis of the wire are plotted in Fig. $6 \mathrm{~b}$ for instants defined in Fig. 6a. Strain profiles are similar to the ones obtained for $\mathrm{CW}$ material. Fig. $6 \mathrm{c}$ shows the global mechanical behaviour of materials B and C. For material C, strain profiles are plotted in Fig. $6 \mathrm{~d}$ for instants defined in Fig. $6 \mathrm{c}$. Strain profiles are similar to the one obtained for material B. Finally, Fig. Ge shows the global mechanical behaviour of materials D and E. For material D, strain profiles are plotted in Fig. $6 f$ for instants defined in Fig. 6e. Strain profiles are similar to the one obtained for material E.

Fig. 7a shows (i) the initial elastic modulus, noted $E_{\text {ini }}$, during the first loading and (ii) the elastic modulus after localisation plateau, noted $E_{\text {end }}$, observed on the stress-strain curves. Slopes to estimate the elastic moduli are sketched in dashed line in Fig. 6. Fig. 7b shows the plateau stresses at loading, unloading and the hysteresis height noted $\sigma_{\text {high }}, \sigma_{\text {low }}$ and $\Delta \sigma$, respectively.

CW material exhibits purely elastic brittle behaviour (Fig. 6a), i.e. stress-strain curve of the material is linear, and no plasticity occurs before failure. Its elastic modulus is estimated to $53 \mathrm{GPa}$. Ultimate tensile strength is about $1500 \mathrm{MPa}$. With short duration heat treatment, the material can be soften. Material A remains purely elastic and brittle with lower elastic modulus estimated to $43 \mathrm{GPa}$. The ultimate tensile strength remains high for metallic material and is about $1500 \mathrm{MPa}$. For these two materials, the strain field is uniform along the wire axis (Fig. 6b).

When increasing heat treatment energy, the materials B and $C$ exhibit classical behaviour of superelastic NiTi SMA without residual strain (Fig. $6 \mathrm{c}$ and d). Stress plateaus due to direct and reverse phase transformations are observed at loading and unloading with an important hysteresis of $\Delta \sigma=200 \mathrm{MPa}$ for the two heat treatments. The stress plateaus are lower for material $C$ because the maximum temperature reached by material $C$ is higher than material $\mathrm{B}$ one. The plateau stresses decreases between first and second cycles and the difference is estimated to $-30 \mathrm{MPa}$ and $-10 \mathrm{MPa}$ for materials $\mathrm{B}$ and $\mathrm{C}$, respectively. For these two materials, classical localisation phenomena are observed during the stress plateau. During the ultimate loading, when the material is stretched to the maximum stress reached during the first cycle, stress drops up to the value of the first cycle plateau. The elastic moduli of first slopes increase with heat treatment duration. It is estimated to $50 \mathrm{GPa}$ and $68 \mathrm{GPa}$ for materials $\mathrm{B}$ and $\mathrm{C}$, respectively. The elastic moduli after stress plateau are estimated to be about $21 \mathrm{GPa}$ and $25 \mathrm{GPa}$ for materials $B$ and $C$, respectively. Ultimate tensile strength is about $1300 \mathrm{MPa}$ for both materials. Stress-strain evolution after the plateau is linear. The material exhibits brittle behaviour.

For materials $\mathrm{D}$ and $\mathrm{E}$, a superelastic behaviour with a residual strain is observed during the first loading, unloading cycle (Fig. 6e and $\mathrm{f}$ ). Their loading plateau stresses are equal to $430 \mathrm{MPa}$ and $450 \mathrm{MPa}$, respectively. Material D plateau stress is lower than C one. 

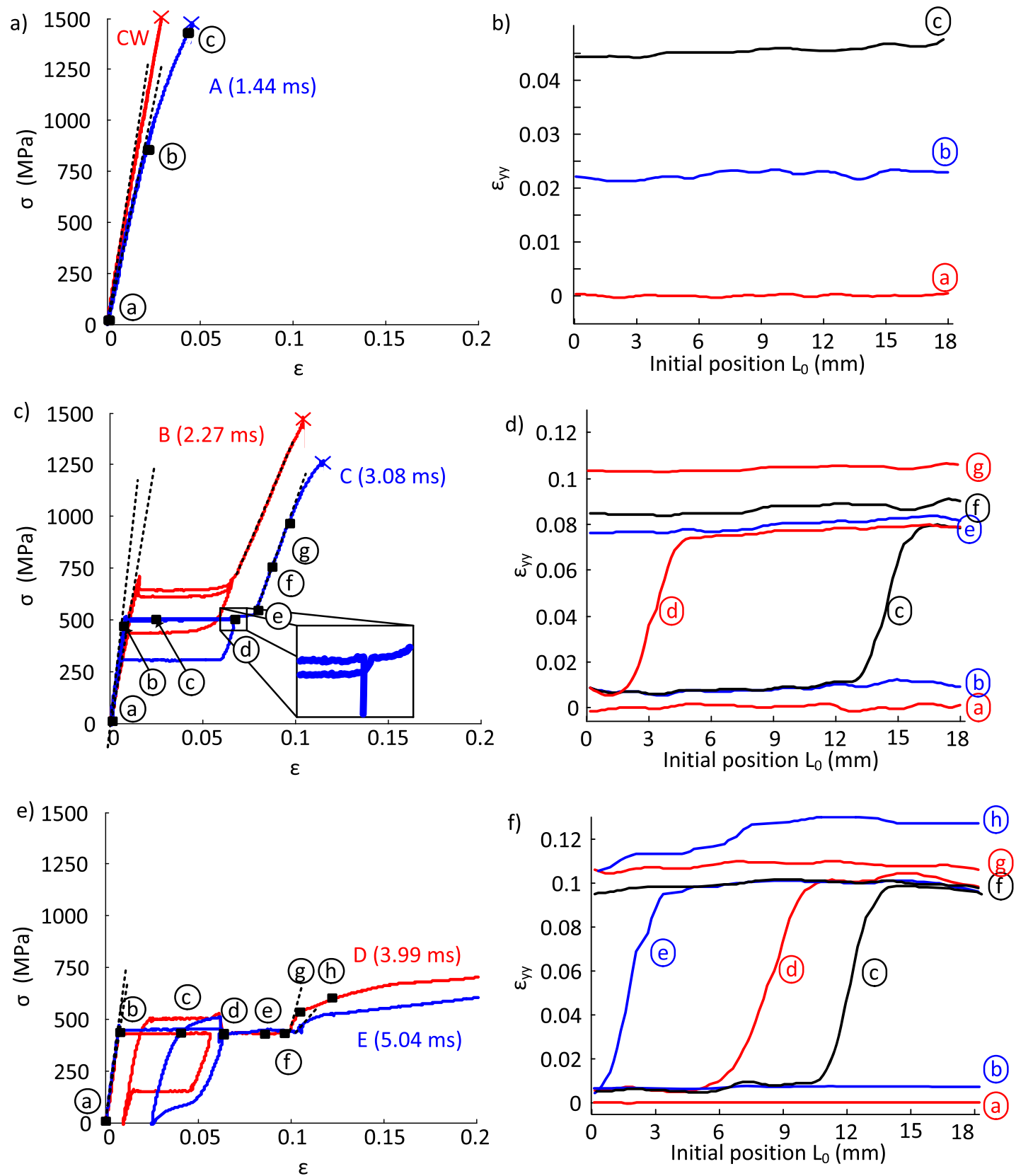

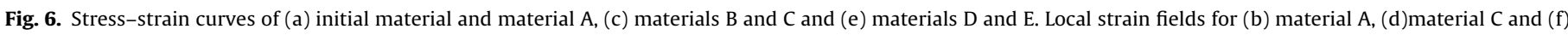
material D.
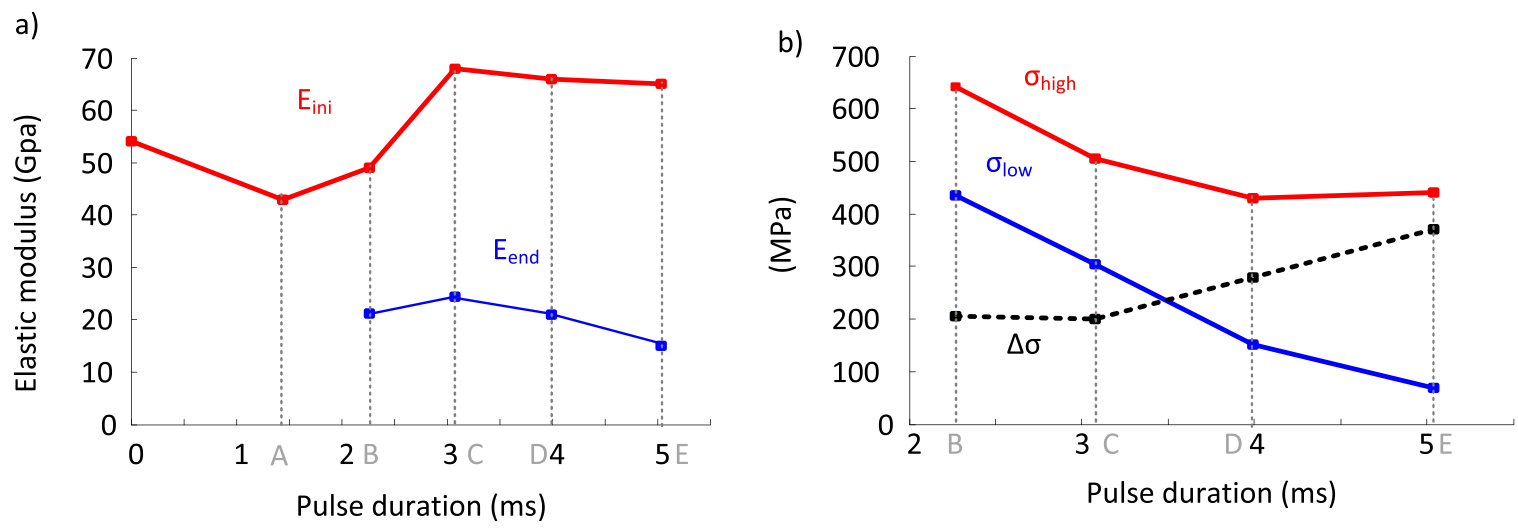

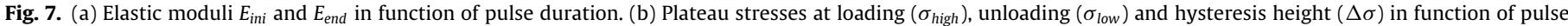
duration. 
It is also lower than material $\mathrm{E}$ one while maximum temperature reached by material $\mathrm{E}$ is higher than material $\mathrm{D}$ one. Elastic moduli during the first slopes are estimated to $63 \mathrm{GPa}$ for the two materials. During the ultimate loading, a non-classical behaviour is observed. When the plateau stress of the first loading is reached, the stress still increases with strain and reaches a plateau to a higher value. Then, when the material is stretched to the maximum strain reached during the first cycle, stress drops down to the stress value of the first cycle plateau. Then, global behaviour is identical to the behaviour observed during the first loading. Finally after the plateau, the elastic moduli presented in Fig. 6e are estimated to $20 \mathrm{GPa}$ and $17 \mathrm{GPa}$ for materials D and E Fig. 7a, respectively. Finally, strain hardening is observed. A maximal strain of $40 \%$ was reached for both materials without failure. During first loading, the local strain field exhibit localisation phenomenon as materials B and C. However, during the second loading, the local strain field is non-uniform with two localisation fronts. This specific local behaviour is not presented here but will be analysed in a forthcoming study. During the strain hardening phase, localisation is observed.

Finally, from Fig. $6 c$ and e, the transformation strain of materials B, C, D and E are estimated to be 5\%, 7\%, $9 \%$ and $10 \%$, respectively. When the pulse time increases, the transformation strain increases too.

\section{Discussion}

\subsection{On the homogeneity of the heat treatment}

In Meng et al. (2013), thermal gradient was observed during $300 \mathrm{~s}$ heat treatment, leading to mechanical graded material. Considering thermal gradient observed during cooling phase of the heat treatment (see Fig. 3), an identical mechanical behaviour could be assumed. However, if local strain behaviours are very different from one to another materials, the heat treatment is uniform along the main axis of the sample. Initially, material A deforms homogeneously as clearly shown in Fig. 6b. For materials B and C, during elastic phases, the strain fields are uniform (Fig. 6d instants a, b, e, f). For all superelastic materials, during the plateau, i.e. when localisation is observed, outside localisation front, the strain is uniform to a high or low strain value (Fig. $6 \mathrm{~d}$ and f). The specific local behaviour of materials D and E during localisation zone and strain hardening, presented in the previous section, is due to the partial pre-straining of the sample during the first loading.

Thus, even if the material temperature during cooling is heterogeneous, materials are heat treated homogeneously. For such heat treatment, the governing parameter is the maximal temperature reached during heating. Such a result is not valid when increasing the duration of heat treatment as observed in Meng et al. (2013).

\subsection{Mechanical properties and microstructure}

Delville et al. (2010, 2011) studied microstructure evolution of identical CW wires during milliseconds electropulse heat treatment. From comparison of Fig. 6 of this study and Fig. 3 of Delville et al. (2010), it is considered that materials A, B, C, D, and E can be compared with materials called $6 \mathrm{~ms}, 10 \mathrm{~ms}, 12 \mathrm{~ms}, 16 \mathrm{~ms}$ and $18 \mathrm{~ms}$ in their paper, respectively. In the following discussion, the microstructure is considered as the one summarised in Table 2, taken from Delville et al. (2010, 2011).

\subsubsection{About materials elasticity}

To begin, observations that $\mathrm{CW}$ and $\mathrm{A}$ materials, i.e. amorphous and polygonised material, have a high elastic potential and exhibits brittle behaviour (Fig. 6a and b) are in good agreement with Sergueeva et al. (2003) and Delville et al. (2010). Sergueeva et al. (2003) showed that amorphous NiTi exhibits classical properties of
Table 2

Comparison with the literature data from Delville et al. (2010, 2011).

\begin{tabular}{llll}
\hline Material & $\begin{array}{l}\text { Sample name in } \\
\text { Delville et al. } \\
(2010)\end{array}$ & Microstructure & Grain size $(\mathrm{nm})$ \\
\hline $\mathrm{CW}$ & $0 \mathrm{~ms}$ & $\begin{array}{l}\text { Mainly austenite } \\
\text { and amorphous }\end{array}$ & - \\
$\mathrm{A}$ & $6 \mathrm{~ms}$ & $\begin{array}{l}\text { Polygonised and } \\
\text { amorphous } \\
\text { Polygonised }\end{array}$ & $5-10$ \\
$\mathrm{~B}$ & $10 \mathrm{~ms}$ & $\begin{array}{l}\text { nanocrystalline } \\
\text { polygonised } \\
\text { nanocrystalline }\end{array}$ & $20-40$ \\
C & $12 \mathrm{~ms}$ & $\begin{array}{l}\text { Recrystallised } \\
\text { Recrystallised }\end{array}$ & $200-700$ \\
D & $16 \mathrm{~ms}$ & $800-1200$ \\
\hline
\end{tabular}

metallic glasses. In the report of Schuh et al. (2007) about mechanical properties of metallic glasses, it is mentioned that the elastic modulus of amorphous material is about 30\% lower than crystallised material. From Fig. 7a it is observed that the difference of elastic modulus between CW and D materials, i.e. partly amorphous and crystallised material is about $20 \%$. The order of magnitude is in good agreement with Schuh et al. (2007) and the difference is assumed to be due to the presence of an important amount of austenite phase in the CW material. Schuh et al. (2007) also indicated that the room temperature elastic modulus decreases with increasing annealing temperature which is in good agreement with measurement of elastic modulus of CW and A materials (Fig. 7a).

Values of elastic modulus $E_{\text {ini }}$ proposed in Fig. 7a for materials B, C, D and E are generally associated to austenite elastic modulus. Results are in good agreement with dispersed values found in the literature comprised between 40 and $90 \mathrm{GPa}$ as mentioned in Liu and Xiang (1998). However, for materials B and C, considering that the material is composed of polygonised material and nanocrystals, these values cannot be associated to Young modulus of crystallised austenite because it can be supposed that nanograins and polygonised part deform in different manner. Values of elastic modulus $E_{\text {end }}$ are generally associated to martensite elastic modulus. Results are in good agreement with dispersed values found in the literature comprised between 20 and $50 \mathrm{GPa}$ as mentioned in Liu and Xiang (1998). The specific mechanical behaviour obtained after superelastic plateau is discussed in Section 4.2.3.

\subsubsection{About superelasticity of materials}

Since several decades, it is known that superelasticity of NiTi SMA is due to the phase transformation from austenite to martensite on the material grains. In the proposed case, it is assumed that identical deformation mechanisms occur in the nanograins and micrograins of B, C and D, E materials, respectively. Other deformation mechanisms such as nanograins rotation and boundary sliding can occur in materials A, B and C, as mentioned in Sergueeva et al. (2003), but cannot be proven or discussed from the proposed results. For materials $\mathrm{D}$ and $\mathrm{E}$, the material is recrystallised and composed of micrograins and it is assumed that the classical deformation mechanisms are observed. The irreversible strain observed in the stress strain curve is due to the sliding of dislocations observed in Delville et al. (2011). Localisation phenomenon (Fig. 6d and f) is also classically associated to the superelastic behaviour obtained in tension.

Results about superelasticity obtained via electropulse heat treatment are in good agreement with the literature about superelasticity obtained via classical heat treatment as in Jiang et al. (2009): increasing heat treatment temperature decreases the plateau stress and increases stress hysteresis (Fig. 7b). For materials $B$ and $C$, the plateau stress decreases with cycling as observed in Liu et al. (2006) and the yield drop phenomenon is observed as in Eucken and Duerig (1989), for example. However, longer 
electropulse heat treatments, as for material D and E, create a unique mechanical behaviour: the plateau stress increases with cycling. This phenomenon is characteristic of electropulse heat treatments and was also observed in Delville et al. (2010). The yield drop phenomenon is also observed but from a higher stress value. For these materials, very specific localisation phenomenon can be observed and it will be developed in an other study.

\subsubsection{Brittle behaviour vs. strain hardening}

In Fig. $6 \mathrm{c}$, for materials $\mathrm{B}$ and $\mathrm{C}$, the ultimate loading is linear and the material is brittle with important tensile strength. This behaviour is similar to the one observed for CW and A materials (Fig. 6a). With classical heat treatments, strain hardening are classically observed in cold worked material directly aged as in Saikrishna et al. (2009) or annealed and aged as in Jiang et al. (2009). Materials having linear and potentially elastic behaviour after transformation plateau, with important tensile strength, have already been observed in Pilch et al. (2009) with Joule heating but have never been obtained with conventional heat treatments to the knowledge of authors. This property is of great interest for SMA engineering.

From Delville et al. (2010, 2011), it is known that materials D and $\mathrm{E}$ are recrystallised into micrograins and that important dislocation phenomenon occurs. This observation is in good agreement with strain hardening observed in Fig. Ge because dislocations create large irreversible deformations with strain hardening of the material. In the profile $h$ of Fig. 6f, localisation is observed. This localisation is due to the pre-straining of the localised area during first loading.

\section{Conclusion}

This study investigated mechanical behaviours of cold worked NiTi wires heat treated with electropulse. From this study, one can conclude that milliseconds electropulse is an efficient method to realise homogeneous heat treatments and allows to adapt the functional properties of cold worked NiTi SMAs. On wire of diameter $0.5 \mathrm{~mm}$, of length $20 \mathrm{~mm}$ and for heat pulse of power $P=3000 \mathrm{~W}$ :

- Low duration heat treatment (1.5 ms) allows to soften the initial cold worked material but preserves the elastic and brittle with a high ultimate tensile strength properties.

- Middle duration heat pulse (2-3 ms) restores the classical superelastic behaviour observed on NiTi SMAs. After the plateau, the material deforms linearly with a brittle behaviour and an important ultimate tensile strength as the initial material: such a property cannot be obtained with classical heat treatments.

- Long duration heat pulse (4-5 ms) allows to obtain a superelastic behaviour with important residual deformation. With cycling, the strain of successive plateaus increases with loading: such a property has never been observed with classical heat treatments. The residual deformation is due to the sliding of dislocations defects in the material. After the plateau, strain hardening is observed.
This study brings important information about mechanical behaviour of cold worked NiTi SMA heat treated with milliseconds electropulses.

\section{Acknowledgement}

The authors wish to acknowledge the financial support of the ANR research programme "Guidage d'une Aiguille Médicale Instrumentée - Déformable” (ANR-12-TECS-0019).

\section{References}

Delville, R., Malard, B., Pilch, J., Sittner, P., Schryvers, D., 2010. Microstructure changes during non-conventional heat treatment of thin Ni-Ti wires by pulsed electric current studied by transmission electron microscopy. Acta Mater. 58, 4503-4515.

Delville, R., Malard, B., Pilch, J., Sittner, P., Schryvers, D., 2011. Transmission electron microscopy investigation of dislocation slip during superelastic cycling of $\mathrm{Ni}-\mathrm{Ti}$ wires. Int. J. Plast. 27, 282-287.

Duerig, T., Pelton, A., Stockel, D., 1999. An overview of nitinol medical applications. Mater. Sci. Eng. A 273, 149-160.

Eucken, S., Duerig, T.W., 1989. The effects of pseudoelastic prestraining on the tensile behaviour and two-way shape memory effect in aged NiTi. Acta Metall. Mater. 37, 2245-2252.

Jiang, F., Liu, Y., Yang, H., Li, L., Zheng, Y., 2009. Effect of ageing treatment on the deformation behaviour of Ti-50.9 at.\% Ni. Acta Mater. 57, 4773-4781.

Jiang, S., Hu, L., Zhang, Y., Liang, Y., 2013. Nanocrystallization and amorphization of NiTi shape memory alloy under severe plastic deformation based on local canning compression. J. Non-Cryst. Solids 367, 23-29.

Jiang, S.Y., Tang, M., Zhao, Y.N., Hu, L., Zhang, Y.G., Liang, Y.L., 2014. Crystallization of amorphous NiTi shape memory alloy fabricated by severe plastic deformation. Trans. Nonferr. Met. Soc. China 24, 1758-1765.

Kurita, T., Matsumoto, H., Abe, H., 2004. Transformation behavior in rolled NiTi. J. Alloys Compd. 381, 158-161.

Liu, Y., Xiang, H., 1998. Apparent modulus of elasticity of near-equiatomic NiTi. J. Alloys Compd. 270, 154-159.

Liu, Y., Mahmud, A., Kursawe, F., Nam, T.H., 2006. Effect of pseudoelastic cycling on the Clausius-Clapeyron relation for stress induced martensitic transformation in NiTi. J. Alloys Compd. 1, 1173-1176.

Malard, B., Pilch, J., Sittner, P., Delville, R., Curfs, C., 2011. In situ investigation of the fast microstructure evolution during electropulse treatment of cold drawn NiTi wires. Acta Mater. 59, 1542-1556.

Meng, Q., Yang, H., Liu, Y., Nam, T.H., Favier, D., 2013. Ti-50.8 at.\% Ni wire with variable mechanical properties created by spatial electrical resistance over-ageing. J. Alloys Compd. 577, 245-250.

Pilch, J., Heller, L., Sittner, P., 2009. Final thermomechanical treatment of thin NiTi filaments for textile applications by electric current. In: Sittner, P., Heller, L., Paidar, V. (Eds.), Esomat 2009 - The Eighth European Symposium on Martensitic Transformation, 2009. EDP Sciences, http://dx.doi.org/10.1051/esomat/200905024 www.esomat.org

Saikrishna, C.N., Ramaiah, K.V., Allam Prabhu, S., Bhaumik, S.K., 2009. On stability of NiTi wire during thermo-mechanical cycling. Bull. Mater. Sci. 32, 343-352.

Sergueeva, A.V., Song, C., Valiev, R.Z., Mukherjee, A.K., 2003. Structure and properties of amorphous and nanocrystalline NiTi prepared by severe plastic deformation and annealing. Mater. Sci. Eng. A 339, 159-165.

Schuh, C.A., Hufnagel, T.C., Ramamurty, U., 2007. Mechanical behavior of amorphous alloys. Acta Mater. 55, 4067-4109.

Smith, J.F., 1993. The heat capacity of NiTi Alloys in the temperature range 120 to 800 K. J. Phase Equilib. 14, 853-860.

Van Humbeeck, J., 1999. Non-medical applications of shape memory alloys. Mater Sci. Eng. A 273, 134-148.

Wang, Y.B., Zheng, Y.F., Liu, Y., 2009. Effect of short time direct current heating on phase transformation and superelasticity of Ti-50.8 at.\% Ni alloy. J. Alloys Compd. 477, 764-767.

Zhu, R.F., Liu, J.N., Tang, G.Y., Shi, S.Q., Fu, M.W., Tse, Z.T.H., 2014. The improved superelasticity of NiTi alloy via electropulsing treatment for minutes. J. Alloys Compd. 584, 225-231. 